\title{
Re: Dry Needling in the Management of Musculoskeletal Pain
}

To the Editor: This article ${ }^{1}$ clearly shows the need for further study into the causes and treatment of myofascial pain syndromes. I have worked personally with Dr. Chan Gunn for 25 years and can attest to the significant changes in function, pain, and quality of life that his method of treatment can bring.

The article by Ceccherelli et $\mathrm{al}^{2}$ is puzzling because, by their definition, "superficial" dry needling ( $2 \mathrm{~mm}$ ) barely penetrated the epidermis, whereas "deep" needling $(15 \mathrm{~mm})$ in the lumbar area is barely sufficient to traverse the superficial dermis and fat. I commonly use needles to a depth of 40 and $50 \mathrm{~mm}$ to reach the rotatores and intertransversalis muscles (the deep central group of multifidi).

As in all clinical trials (let alone meta-analyses), the problem of "classification" may be the primary confounding issue. There are so many potential irritating impulses in the peripheral tissues, and so many amplification possibilities in the central system, that further study must include clarification of the physiologic causes of chronic myofascial pain. Once we have a basic premise, observational studies (not necessarily blinded) will help to prove or disprove the central thesis. However, the most important element will always be the adequate physical examination of the patient for identification of involved muscles. "Nonspecific low back pain" is not an adequate diagnosis on which to determine success or failure of a treatment!
Personally, using Gunn's3 approach (paraspinal pressure on dorsal root ganglia causes a functional neuropathy that causes distal muscles to become supersensitive and therefore a myofascial pain problem) has been very successful in alleviating pain in my everyday practice. Dry needling is a relatively quick, very "low-tech," easily learned technique. The results are also very gratifying to the practitioner when a major pain is reduced to a small pain or no pain at all after a brief intervention during an office visit!

$$
\begin{array}{r}
\text { John Kent, BSc, MD, CCFP, FCFP } \\
\text { Family Medicine Pain Relief Unit } \\
\text { Rambam Hospital } \\
\text { Haifa, Israel } \\
\text { kent@netmedia.net.il }
\end{array}
$$

\section{References}

1. Kalichman L, Vulfsons S. Dry needling in the management of musculoskeletal pain. J Am Board Fam Med 2010;23:640-6.

2. Ceccherelli F, Rigoni MT, Gagliardi G, Ruzzante L. Comparison of superficial and deep acupuncture in the treatment of lumbar myofascial pain: a doubleblind randomized controlled study. Clin J Pain 2002; 18:149-53.

3. Gunn CC. Radiculopathic pain: diagnosis, treatment of segmental irritation or sensitization. J Musculoskel Pain 1997;5:119-34.

doi: 10.3122/jabfm.2011.01.100239 